\title{
Replacement of the same lumen-apposing metallic stent for multiple necrosectomy sessions
}

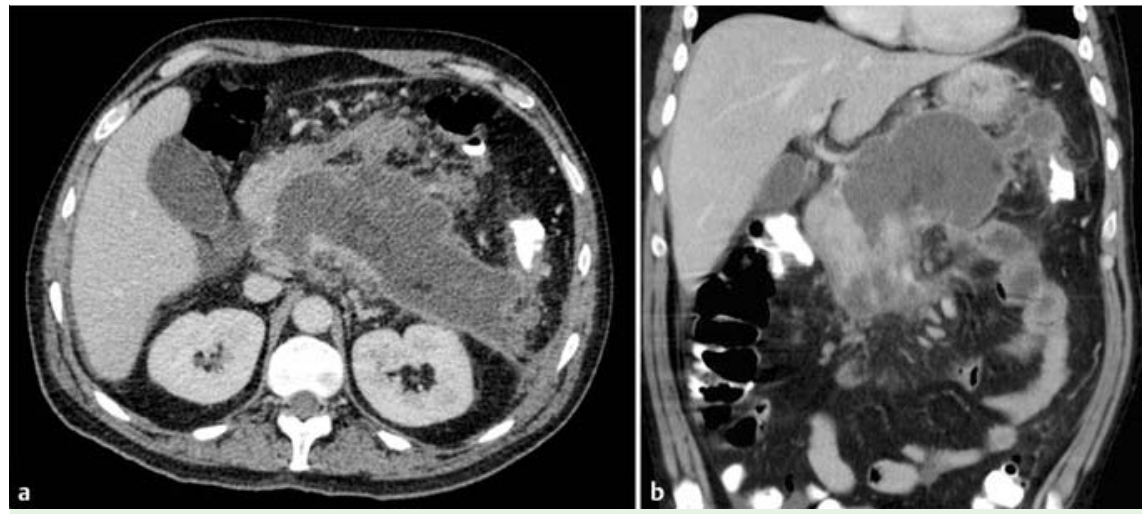

Fig. 1 Computed tomographic scans showing walled-off pancreatic necrosis in a 45 -year-old patient 4 weeks after acute pancreatitis. a Axial view. b Coronal view.

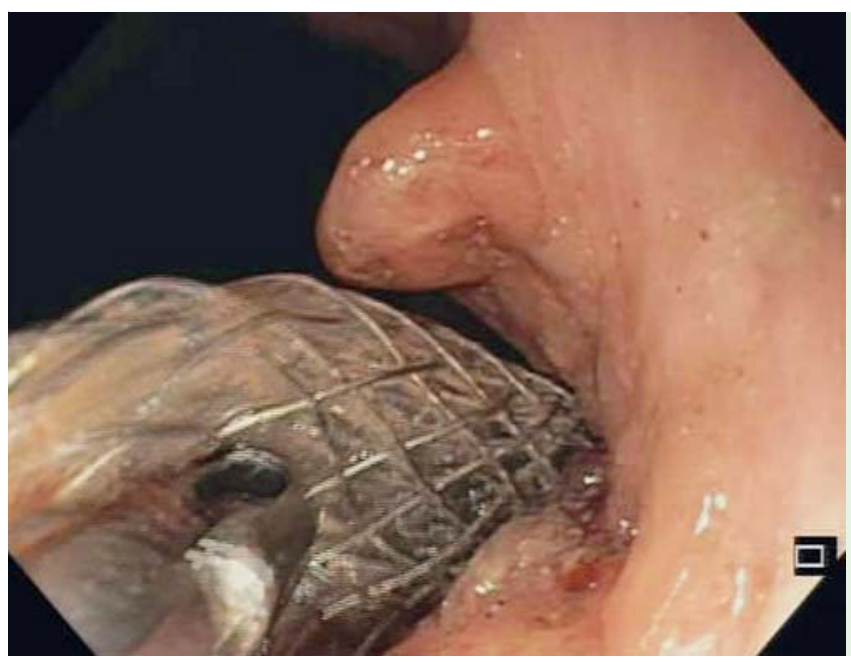

Fig. 2 Deployment of the stent with a grasping forceps after a necrosectomy session.

Necrosectomy through a metal stent is feasible [1] but can be hindered by the limited mobility of the scope tip, and accidental removal of the stent during the extraction or fragmentation of necrotic material is not uncommon [2-4]. We describe a technique for removing and replacing the same lumen-apposing stent before and after each session of necrosectomy.

A 45-year-old patient with severe alcoholic acute pancreatitis required readmission for fever and leukocytosis. Urgent computed tomography revealed walledoff pancreatic necrosis ( $\bullet$ Fig. 1 ). Endoscopic ultrasound-guided transgastric drainage was carried out with the Hot Axios system (Xlumena, Mountain View, California, USA) and a $15 \times 10-\mathrm{mm}$ stent. Eight endoscopic necrosectomy sessions were needed.

Because of the density of the necrotic material, the first three sessions consisted of intense lavage and small fragmentation. During the following two sessions, fragmentation and extraction of the necrotic material were more effective, but the stent was accidentally removed. We replaced the same stent at the end of the procedures ( $\bullet$ Fig. 2 , Video 1). During the remaining three sessions, the stent was intentionally retrieved at the begin-

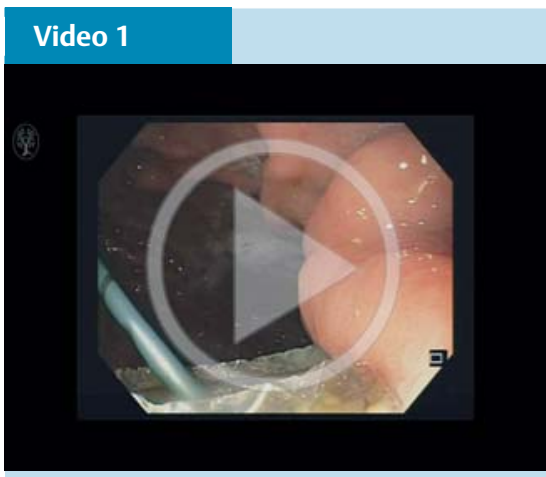

Removal and replacement of the same lumenapposing metallic stent for multiple necrosectomy sessions.

ning of each procedure and then put back. Computed tomography 2.5 months after the last session showed complete resolution of the necrosis, and the stent was retrieved.

Stent removal before a necrosectomy session may be justified in specific cases for several reasons. The first is to improve maneuverability inside the collection, which is often limited by the stent. The second is to avoid accidental removal of the stent, which can degrade the stent covering. Intentional removal of the stent may prevent such degradation. A third reason is the need to extract a larger amount of necrotic material; the amount extracted is limited by the inner diameter of the stent.

A possible concern about this procedure is the possibility of damaging the working channel of the endoscope. However, this stent can be inserted smoothly and easily inside the distal tip of a gastroscope. For a smaller channel, lubrication with silicone or oil may be adequate.

Replacing the same Axios stent for multiple necrosectomy sessions appears to be safe and effective. Intentional removal of the stent should be considered when a large necrosectomy is done.

Endoscopy_UCTN_Code_TTT_1AR_2AI

Competing interests: None 
Carlos Guarner-Argente ${ }^{1}$, Juan

Colán-Hernández ${ }^{1}$, Mar Concepción-

Martín', Miguel Martínez-Guillén', German Soriano ${ }^{1,2}$, Sergio Sainz ${ }^{1}$, Carlos Guarner ${ }^{1,2}$

${ }^{1}$ Gastroenterology Department, Hospital de la Santa Creu i Sant Pau, Institut de Reçerca - IIB Sant Pau, Universitat Autònoma de Barcelona, Barcelona, Spain

${ }^{2}$ CIBERehd Instituto de Salud Carlos III, Madrid, Spain

\section{Acknowledgment \\ $\nabla$}

Carlos Guarner-Argente received financial support from the Societat Catalana de Digestologia (beca per la Intensificació a la recerca).

\section{References}

1 Gornals JB, De la Serna-Higuera C, SánchezYague $A$ et al. Endosonography-guided drainage of pancreatic fluid collections with a novel lumen-apposing stent. Surg Endosc 2013; 27: 1428-1434

2 Mukai S, Itoi T, Baron TH et al. Endoscopic ultrasound-guided placement of plastic vs. biflanged metal stents for therapy of walled-off necrosis: a retrospective singlecenter series. Endoscopy 2015; 47: 47-55

3 Walter D, Will $U$, Sanchez-Yague A et al. A novel lumen-apposing metal stent for endoscopic ultrasound-guided drainage of pancreatic fluid collections: a prospective cohort study. Endoscopy 2015; 47: 63-67

4 Chandran S, Efthymiou M, Kaffes $A$ et al. Management of pancreatic collections with a novel endoscopically placed fully covered self-expandable metal stent: a national experience (with videos). Gastrointest Endosc 2015; 81: 127-135
Bibliography

Dol http://dx.doi.org/

10.1055/s-0034-1392788

Endoscopy 2015; 47: E447-E448

(c) Georg Thieme Verlag KG

Stuttgart · New York

ISSN 0013-726X

\section{Corresponding author}

Carlos Guarner-Argente, MD, PhD

Gastroenterology Department

Hospital de la Santa Creu i Sant Pau Universitat Autònoma de Barcelona Sant Quintí, 89

08041 Barcelona

Spain

Fax: +34-93-556-5608

cguarnera@santpau.cat 